\title{
La exportación de cueros, lana y tasajo a través del puerto de Buenos Aires entre 1835 y 1854
}

Miguel A. Rosal

(CONICET-Instituto “E. Ravignani”)

En el contexto de la división internacional del trabajo implementada a partir del siglo XVIII y acentuada a lo largo de la siguiente centuria, donde algunas naciones, la mayoría, aportaban materias primas que motorizaban la industrialización europea, muy especialmente la inglesa, y otras, unas pocas, introducían en el mercado mundial productos manufacturados, el Río de la Plata participará decididamente a partir de 1810 únicamente como proveedora de productos primarios provenientes de su ganadería, privado ya de los flujos de la plata potosina, principal bien exportable durante la época colonial, dada la incapacidad de los porteños para controlar militarmente la región altoperuana.

En ese sentido, la presente investigación intentará mostrar algunos de los aspectos sobresalientes de la comercialización de los bienes pecuarios más significativos de la región rioplatense, así como también se harán ciertas consideraciones acerca de la valoración de las exportaciones y del destino de los frutos en cuestión.

\section{Introducción}

El objetivo que intenta alcanzar este trabajo es ilustrar sobre algunos aspectos de las exportaciones rioplatenses en el marco, por una parte, de la gran expansión de la economía y del comercio de Europa occidental, principalmente, y de Norteamérica, en segundo término, hacia el resto del planeta en búsqueda de mercados para la producción industrial en crecimiento; y por otra parte, de los cambios que resultaron de las gestas independentistas americanas.

El patrón del comercio exterior argentino, tal como le sucedió a gran parte de los países latinoamericanos, significó una suerte de continuación de aquél que dominaba a fines de la época colonial, es decir que la incorporación a la economía mundial se produjo sin que se efectuaran cambios en la estructura económica preexistente.

* Agradezco los comentarios que, sobre una versión previa, realizó Jorge Gelman. También agradezco los que hicieron José Carlos Chiaramonte y Juan Carlos Garavaglia a la presentada en las XV Jornadas de Historia Económica, Tandil, 9-11 de octubre de 1996. 
Sin embargo, en el caso puntual del Río de la Plata, el movimiento revolucionario de 1810 y las guerras de Independencia que el mismo trajo aparejadas produjeron la fractura del nexo Potosí-Buenos Aires por donde circulaba el flujo metálico altoperuano, principal exportación del período hispánico.

Seguirá, entonces, en su condición de proveedor de bienes primarios - los pecuarios, los cuales pasan a conformar casi exclusivamente el total de las exportaciones- que alimentarán la industrialización europea, a la vez que será creciente consumidor de las manufacturas provenientes de Ultramar, dentro de una estructura comercial mundial donde la división internacional del trabajo estaba claramente establecida. ${ }^{1}$

Las consecuencias de la liberalización comercial que siguió al proceso abierto en mayo de 1810 fueron nefastas para algunas artesanías del Interior, en especial para la del textil de algodón catamarqueño ${ }^{2}$ y para la vitivinícola cuyana ${ }^{3}$ - aunque en esta última mucho tuvieron que ver las luchas civiles-, pues tendrán que afrontar una competencia desfavorable, dadas la baratura y mejor calidad de los productos europeos, si bien otras, como la artesanía textil de lana de Córdoba y Santiago del Estero, corrieron con mejor suerte. ${ }^{4}$

El Litoral de los Ríos, por su parte, se vio beneficiado con esta articulación incondicional con los mercados atlánticos, aunque nunca dejará de reclamar la libre navegación de los ríos, el cese de la intermediación porteña, el reparto equitativo de la recaudación aduanera y, en fin, la organi-

1 Herrera Canales, Inés: El comercio exterior de México, 1821-1875, México, 1977, páginas 3-22. Sobre el comercio exterior del Perú se puede consultar, entre otros, el trabajo de Bonilla, Heraclio: "La coyuntura comercial del siglo XIX en el Perú", en Desarrollo Económico, v. 12, n 46, Buenos Aires, julio-septiembre de 1972, págs. 305-331. Sobre nuestro país, para un período anterior al que nosotros tratamos, existe el trabajo de Merediz, Rodolfo: "Comercio de frutos del país entre Buenos Aires y mercados europeos entre 1815 y 1820”, Trabajos y Comunicaciones, no 16, La Plata, 1966, págs. 136-152.

2 Halperín Donghi, Tulio: Revolución y guerra. Formación de una élite dirigente en la Argentina criolla, Buenos Aires, 1972, pág. 108.

3 Amaral, Samuel: "Comercio libre y economías regionales. San Juan y Mendoza, 17801820”, Jahrbuch für Geschichte von Staat, Wirtschaft und Gesellschaft Lateinamerikas, band 27, Köln, 1990, págs. 1-67.

4 Halperín Donghi: De la revolución de Independencia a la confederación rosista, Buenos Aires, 1980, págs. 155-156. Garavaglia, Juan Carlos y Wentzel, Claudia: "Un nuevo aporte a la historia del textil colonial: los ponchos frente al mercado porteño (1750-1850)", Anuario IEHS, n. ${ }^{\circ} 4$, Tandil, 1990, págs. 211-241. Rosal, Miguel Ángel: "El Interior frente a Buenos Aires: flujos comerciales e integración económica, 1831-1850”, Secuencia, n. 31, México, enero-abril de 1995, págs. 51-111; dicho trabajo fue publicado también en Rosal y Schmit, Roberto: "Comercio, mercados e integración económica en la Argentina del siglo XIX”, Cuadernos del Instituto Ravignani, n. 9, Buenos Aires, 1995, págs. 5-61. 
zación nacional regida por una constitución, temas que interesaban poco a Buenos Aires. ${ }^{5}$

Esta, indiferente a la situación por la que pasaban las provincias hermanas, especialmente las de las regiones interiores, gozaba de un período de crecimiento económico, cuya base estaba conformada por un significativo desenvolvimiento ganadero, apuntalado por una constante expansión territorial; disponía, además, de los ingresos aduaneros, los cuales se veían incrementados gracias a la implementación de una política arancelaria acorde a los intereses porteños, y retenía los servicios de intermediación al prohibir la libre navegación de los ríos. ${ }^{6}$

La investigación que hemos llevado a cabo durante los últimos años nos ha permitido apreciar con bastante nitidez la dinámica de los flujos comerciales que desde el Interior se dirigían al puerto de Buenos Aires durante la extensa etapa rosista y de este modo alcanzar a comprender el grado de articulación de todo el espacio rioplatense con la capital de la Confederación. ${ }^{7}$ A pesar de los avances realizados en la pesquisa, prácticamente no tenemos noticia alguna de la región que se convirtió a lo largo de la primera mitad del siglo XIX en la principal proveedora de los productos ganaderos con destino a los mercados de Ultramar, es decir, la campaña bonaerense, en especial la del sur.

Creemos que la forma más eficaz de acercarse a este problema es a través del estudio de las exportaciones porteñas, pues a las mismas sólo bastaría restarles los aportes del Interior para vislumbrar el de la campaña de Buenos Aires - tema sobre el cual ya hemos hecho algunas aproximaciones en nuestros recientes trabajos - y poder ponderar de este modo el real desenvolvimiento económico de las tierras al sur del Salado, el ascenso - irrefutable, sin duda- de Entre Ríos y, en suma, la importancia que van adquiriendo las distintas regiones del espacio rioplatense y el peso que cada una tiene en cuanto a sus aportes al flujo exportador.

5 Chiaramonte, José Carlos: Mercaderes del Litoral. Economía y Sociedad en la provincia de Corrientes, primera mitad del siglo XIX, México, 1991. Schmit: "Mercados y flujos comerciales en los estados provinciales argentinos de la primera mitad del siglo XIX. El comercio de Corrientes a Buenos Aires, (1822-1833)", Boletín del Instituto de Historia Argentina y Americana "Doctor Emilio Ravignani”, 3ra. serie, n. ${ }^{\circ} 4$, Buenos Aires, segundo semestre de 1991, págs. 31-61 y "Comercio y mercado en el Litoral argentino durante la primera mitad del siglo XIX", en Rosal y Schmit: Comercio, mercados e integración económica..., págs. 63-88.

6 Halperín Donghi: "La expansión ganadera en la campaña de Buenos Aires (1810-1852)" Desarrollo Económico, v. 3, n. ${ }^{\circ}$ 1-2, Buenos Aires, abril-septiembre de 1963, págs 57-110. Burgin, Miron: Aspectos económicos del federalismo argentino, Buenos Aires, 1987.

7 Sobre la cuestión se puede consultar nuestro trabajo "El Interior frente a Buenos Aires...". 
Otra de las cuestiones a considerar sería la dinámica que se va estableciendo entre los principales productos pecuarios que componen las exportaciones. El papel preponderante de los cueros vacunos, el que desempeñan los cueros baguales, el constante ascenso de la producción de carne salada y la consolidación paulatina de los flujos de lana, en especial a partir de la década del 40.

Por último, el estudio que nos proponemos realizar, junto al que ya hemos efectuado, nos permitirá, creemos, visualizar una continuidad más que un rompimiento en la Argentina del siglo XIX —un país en gestación-, teniendo en cuenta que son las bases económicas implementadas en la primera mitad de la centuria, las que finalmente adquirirían un desarrollo espectacular en la segunda.

\section{Las fuentes}

Tres han sido las principales fuentes consultadas para realizar este trabajo: a) el Registro Oficial de la Provincia de Buenos Aires, correspondiente a los años 1835-primer semestre de 1840, editado entre 1836 y 1841; b) la "Salida", conservada en el Archivo General de la Nación, División Nacional, Sección Contaduría, Receptoría, Cargo y Data, Cargo, sala III, 24-5-5 a 25-5-7, n. ${ }^{\circ} 23-94$, entre 1840 y junio de 1848; y c) la obra de Woodbine Parish, a partir de julio de 1848.

El Registro Oficial nos proporciona datos sobre las "salidas marítimas" entre 1835 y junio de 1840, información dividida en semestres; sólo para el primero de 1835 existe una desagregación de aquélla según la bandera de los barcos que efectuaron el tráfico.

El hecho de que también brinde un pormenor de las "entradas terrestres" - las mercancías que desde el Interior se dirigían a Buenos Aires- a partir del segundo semestre de 1836, por un lado, convierte a esta fuente en una significativa y casi única herramienta para evaluar el comercio interno de buena parte del período, ${ }^{8}$ y por otro, permite realizar algunas consideraciones sobre la interacción de ambos flujos mercantiles.

8 En efecto, en septiembre de 1835, como un adelanto a la Ley de Aduana de fines del citado año, se había dejado de cobrar la Contribución Directa -una excelente fuente para estudiar el comercio interno de Buenos Aires- a los productos involucrados en dicho tráfico (con excepción de la yerba y el tabaco) y la misma no comenzaría a percibirse nuevamente hasta mayo de 1839 . 
La "Salida" se refiere concretamente a la exportación de mercancías desde el puerto de Buenos Aires. Consta, por lo general, de tres partes. La primera es la que nosotros denominamos Permiso, Nota o Manifiesto de Embarque, por el cual se pide autorización para cargar diversos productos y en la que se hace un resumen de lo realmente embarcado - que no necesariamente coincide con los frutos y/o cantidades de los mismos que se solicitaron cargar - y se registran los derechos de "salida" que debe pagar cada mercancía. ${ }^{9}$ La segunda es una solicitud, en parte impresa, que se completa con lo que se desea embarcar, y en donde constará, eventualmente, un pormenor de todo lo que finalmente se cargó. La tercera, no siempre existente, es la "Declaración de lanchero", también en parte impresa, y en donde se indica la carga trasladada desde la Aduana al buque de Ultramar - recordemos que las condiciones de entonces del puerto de Buenos Aires no permitían fondear a las grandes naves-; sin embargo, los datos allí registrados no siempre coinciden con los de las anteriores, por lo que no nos resultan del todo confiables. En caso de divergencias, nos guiamos, principalmente, por la Nota de Embarque, ${ }^{10}$ ya que en ella se asentaban, como hemos dicho, los impuestos correspondientes. Por último, debemos decir que se cotejaron los datos de la "Salida" con los del Registro Oficial de la Provincia de Buenos Aires entre julio de 1839 y junio de 1840 y se obtuvieron series similares, por lo que estaría establecida, en términos generales, la confiabilidad de la fuente utilizada.

La obra de Parish es bien conocida; de ella se pueden extraer, entre otros datos, las cantidades de las mercancías exportadas entre julio de 1848 y junio de 1854, el valor de los frutos entre la primera de las fechas citadas y 1851 , y el destino de los productos entre 1850 y $1853 .^{11}$

En el cuadro 2 -referido a los aportes del Interior y de la campaña de Buenos Aires en el total de las exportaciones - se utiliza, en el caso del flujo del comercio interior, el Registro Oficial hasta 1839, y Cargo y Data, Contribución, entre 1840 y 1850; no se consignan los datos de 1839 pues,

9 Los cueros vacunos (secos, salados, de desecho, etc), al igual que los baguales y cueros de becerro, pagaban un peso; los nonatos, dos reales; el tasajo, las astas, la cerda, el sebo en rama, las pieles de nutria, etc., el $4 \%$ del aforo de dichos productos; y la lana, los cueros de carnero y el sebo derretido, estaban libres de derechos.

10 En ocasiones aparecen como embarcados productos que no están registrados en la Nota; en esos casos, lo supuestamente cargado no es tomado en cuenta.

11 Para el primer semestre de 1854 Parish sólo consigna el número de buques (y el total del tonelaje) según su destino. Parish, Woodbine: Buenos Aires y las provincias del Río de la Plata, Buenos Aires, 1958, págs. 512-517 y 622; en la página 511 se pueden encontrar las cantidades de los productos exportados y el valor de los mismos para los años 1822, 1825, 1829 y 1837. 
según información del Registro Oficial, las Entradas terrestres superan a las Salidas marítimas, excepto en el caso del tasajo; en 1840 y 1844 sucede algo similar con la lana.

Las cifras de exportación de 1840, consignadas en el cuadro 1, corresponden, a su vez, al Registro Oficial (el primer semestre) y a Cargo y Data, Salida (el segundo).

\section{Buenos Aires frente al interior}

De los datos obtenidos en nuestro trabajo sobre el comercio que desde el Interior se dirigía a Buenos Aires se desprende que el Litoral es la región que más fuertes nexos ha entretejido con el puerto, y a través de él, con el mercado ultramarino, cuya creciente demanda de materias primas de origen pecuario garantizaba el constante desenvolvimiento de las provincias litoraleñas. Por el contrario, las regiones del centro y la cuyana - las otras dos en que dividimos el espacio rioplatense para analizar los flujos mercantiles del Interior - se encuentran en ese aspecto mucho más rezagadas, notándose un debilitamiento de los lazos entre dichas regiones y Buenos Aires.

Dentro del Litoral, Entre Ríos es sin duda la provincia más pujante, con un interesante equilibrio en el desempeño económico de las dos grandes zonas en que la seccionamos: la occidental, sobre el río Paraná, y la oriental, sobre el río Uruguay. El dinamismo observado en esta última, sumado al que se desarrolla en la orilla de enfrente, territorio de la antigua Banda Oriental, permite concluir que el eje del tráfico comercial rioplatense se ha trasladado desde la primera - donde se ubicó hasta iniciada la década del 30 - a la segunda de las vías fluviales mencionadas. De las restantes sub-regiones, sólo Santa Fe muestra, luego de la crisis en que estuvo inmersa en los 20, algunos signos de recuperación a lo largo del período; Corrientes, por su parte, se vio perjudicada en su progreso económico dados los constantes conflictos que mantenía con el poder rosista.

De la región Central no hay mucho para decir; si bien Córdoba continúa siendo la región más firmemente vinculada al Atlántico ${ }^{12}$ hemos notado que se ha producido un paulatino retroceso en su porcentaje de participación en la composición total del monto comerciado a lo largo del período, situación que se repite en las restantes sub-regiones, las cuales tra-

12 Assadourian, Carlos Sempat: "El sector exportador de una economía regional del interior argentino. Córdoba. 1800-1860. (Esquema cuantitativo y formas de producción)", en El sistema de la economía colonial. El mercado interior. Regiones y espacio económico, México, 1983, págs. 307-367. 
tan de involucrarse en los distintos circuitos mercantiles surgidos del reacomodamiento del sistema económico luego del final de las guerras de Independencia, pero sobre este tema no tenemos cifras precisas. ${ }^{13}$

\section{CUADRO 1: EXPORTACIÓN DE CUEROS VACUNOS Y BAGUALES, DE LANA Y DE TASAJO POR EL PUERTO DE BUENOS AIRES, 1835-1854}

\begin{tabular}{lrrrr} 
Años & Cueros vacunos & Cueros baguales & Lana & Tasajo \\
\hline 1835 & 534.213 & 20.813 & 130.308 & 119.017 \\
1836 & 622.702 & 40.100 & 132.580 & 150.579 \\
1837 & 823.635 & 25.367 & 164.706 & 178.877 \\
1838 & 355.993 & 20.443 & 166.796 & 165.304 \\
1839 & 8.501 & 1.320 & 25.028 & 6.670 \\
1840 & 83.779 & 4.807 & 3.818 & 8.630 \\
1841 & 2.340 .638 & 113.192 & 304.872 & 217.671 \\
1842 & 1.399 .471 & 58.508 & 124.696 & 133.795 \\
1843 & 2.054 .715 & 71.804 & 172.635 & 182.940 \\
1844 & 1.786 .351 & 41.646 & 139.215 & 328.182 \\
1845 & 1.942 .297 & 69.412 & 172.509 & 274.330 \\
1846 & 436.739 & 54.863 & 65.197 & 21.298 \\
1847 & 1.545 .307 & 108.183 & 317.102 & 225.481 \\
1848 & 1.384 .790 & 93.810 & 507.300 & 314.352 \\
1849 & 2.961 .342 & 238.514 & 934.780 & 559.969 \\
1850 & 2.424 .251 & 187.107 & 739.550 & 390.731 \\
1851 & 2.601 .140 & 140.677 & 769.090 & 431.873 \\
1852 & 1.976 .173 & 47.371 & 724.268 & 521.975 \\
1853 & 1.199 .935 & 151.370 & 808.999 & 335.165 \\
$1854 *$ & 759.968 & 110.828 & 485.380 & 157.998
\end{tabular}

* Datos sólo del primer semestre.

Fuente 1835-junio de 1840: registro oficial de la provincia de Buenos Aires, 1836-1841.

Fuente julio de 1840-junio de 1848: AGN, división nacional, sección Contaduría, receptoría, cargo y data, julio 1840-junio 1848, núms. 24-94, cargo, salida, III, 24-5-6 a 25-5-7; (sobre un total de 10.019 permisos de embarque).

Fuente julio de 1848-junio de 1854: Parish: Buenos Aires y las provincias..., págs. 512-513 y 622.

Nota: Los cueros vacunos y baguales incluyen secos y salados. La lana está expresada en arrobas; el fardo y el bolsón se estiman en 35 arrobas. El tasajo está expresado en quintales.

13 Langer, Erick: "Espacios coloniales y economías nacionales: Bolivia y el norte argentino (1810-1930)", Siglo XIX, año II, n. 4, Monterrey, julio-diciembre de 1987, págs. 144-145. Langer y Conti, Viviana: "Circuitos comerciales tradicionales y cambio económico en los Andes centromeridionales (1830-1930)”, Desarrollo Económico, vol. 31, n. ${ }^{\circ}$ 121, Buenos Aires, abril-junio de 1991, pág. 93. 
MIGUEL ÁNGEL ROSAL

CUADRO 2: EXPORTACIONES DEL PUERTO DE BUENOS AIRES. EL INTERIOR FRENTE A LA CAMPAÑA BONAERENSE, 1836-1850

\section{CUEROS VACUNOS}

\begin{tabular}{lrrrrr} 
& Exportación & Prod. interior & $\%$ & Prod. Bs. As. & $\%$ \\
\hline $1836^{*}$ & 419.921 & 175.854 & 41,88 & 244.067 & 58,12 \\
1837 & 823.635 & 352.905 & 42,85 & 470.730 & 57,15 \\
1838 & 355.993 & 136.086 & 38,23 & 219.907 & 61,77 \\
1839 & - & - & - & - & - \\
1840 & 83.779 & 13.808 & 16,48 & 69.971 & 83,52 \\
1841 & 2.340 .638 & 568.675 & 24,30 & 1.771 .963 & 75,70 \\
1842 & 1.399 .471 & 515.485 & 36,83 & 883.986 & 63,17 \\
1843 & 2.054 .715 & 943.497 & 45,92 & 1.111 .218 & 54,08 \\
1844 & 1.786 .351 & 750.280 & 42,00 & 1.036 .071 & 58,00 \\
1845 & 1.942 .297 & 506.560 & 26,08 & 1.435 .737 & 73,92 \\
1846 & 436.739 & 20.656 & 4,73 & 416.083 & 95,27 \\
1847 & 1.545 .307 & 76.073 & 4,92 & 1.469 .234 & 95,08 \\
1848 & 1.384 .790 & 472.318 & 34,11 & 912.472 & 65,89 \\
1849 & 2.961 .342 & 769.002 & 25,97 & 2.192 .340 & 74,03 \\
1850 & 2.424 .251 & 864.731 & 35,67 & 1.559 .520 & 64,33
\end{tabular}

\section{CUEROS BAGUALES}

\begin{tabular}{lrrrrr} 
& Exportación & Prod. Interior & $\%$ & Prod. Bs. As. & $\%$ \\
\hline $1836 *$ & 18.472 & 5.184 & 28,06 & 13.288 & 71,94 \\
1837 & 25.367 & 13.626 & 53,72 & 11.741 & 46,28 \\
1838 & 20.443 & 5.056 & 24,73 & 15.387 & 75,27 \\
1839 & - & - & - & - & - \\
1840 & 4.807 & 0 & 0,00 & 4.807 & 100,00 \\
1841 & 113.192 & 10.102 & 8,92 & 103.090 & 91,08 \\
1842 & 58.508 & 19.398 & 33,15 & 39.110 & 66,85 \\
1843 & 71.804 & 5.011 & 6,98 & 66.793 & 93,02 \\
1844 & 41.646 & 8.681 & 20,84 & 32.965 & 79,16 \\
1845 & 69.412 & 22.483 & 32,39 & 46.929 & 67,61 \\
1846 & 54.863 & 600 & 1,09 & 54.263 & 98,91 \\
1847 & 108.183 & 200 & 0,18 & 107.983 & 99,82 \\
1848 & 93.810 & 31.930 & 34,04 & 61.880 & 65,96 \\
1849 & 238.514 & 170.714 & 71,57 & 67.800 & 28,43 \\
1850 & 187.107 & 113.342 & 60,58 & 73.765 & 39,42
\end{tabular}


EXPORTACIONES DEL PUERTO DE BUENOS AIRES ENTRE 1835 Y 1854

CUADRO 2: EXPORTACIONES DEL PUERTO DE BUENOS AIRES. EL INTERIOR

FRENTE A LA CAMPAÑA BONAERENSE, 1836-1850 (continuación)

LANA

\begin{tabular}{lrrrrr} 
& Exportación & Prod. interior & $\%$ & Prod. Bs. As. & $\%$ \\
\hline $1836^{*}$ & 40.329 & 21.840 & 54,15 & 18.489 & 45,85 \\
1837 & 164.706 & 66.021 & 40,08 & 98.685 & 59,92 \\
1838 & 166.796 & 38.775 & 23,25 & 128.021 & 76,75 \\
1839 & - & - & - & - & - \\
1840 & - & - & - & - & - \\
1841 & 304.872 & 70.806 & 23,22 & 234.066 & 76,78 \\
1842 & 124.696 & 66.190 & 53,08 & 58.506 & 46,92 \\
1843 & 172.635 & 146.853 & 85,07 & 25.782 & 14,93 \\
1844 & - & - & - & - & - \\
1845 & 172.509 & 138.219 & 80,12 & 34.290 & 19,88 \\
1846 & 65.197 & 50.801 & 77,92 & 14.396 & 22,08 \\
1847 & 317.102 & 40.551 & 12,79 & 276.551 & 87,21 \\
1848 & 507.300 & 102.101 & 20,13 & 405.199 & 79,87 \\
1849 & 934.780 & 133.521 & 14,28 & 801.259 & 85,72 \\
1850 & 739.550 & 113.729 & 15,38 & 625.821 & 84,62
\end{tabular}

TASAJO

\begin{tabular}{lrrrrr} 
& Exportación & Prod. interior & $\%$ & Prod. Bs. As. & \multicolumn{1}{c}{$\%$} \\
\hline $1836^{*}$ & 107.979 & 43.509 & 40,29 & 64.470 & 59,71 \\
1837 & 178.877 & 88.611 & 49,54 & 90.266 & 50,46 \\
1838 & 165.304 & 27.025 & 16,35 & 138.279 & 83,65 \\
1839 & 6.670 & 250 & 3,75 & 6.420 & 96,25 \\
1840 & 8.630 & 0 & 0,00 & 8.630 & 100,00 \\
1841 & 217.671 & 14.725 & 6,76 & 202.946 & 93,24 \\
1842 & 133.795 & 3.215 & 2,40 & 130.580 & 97,60 \\
1843 & 182.940 & 8.025 & 4,39 & 174.915 & 95,61 \\
1844 & 328.182 & 330 & 0,10 & 327.852 & 99,90 \\
1845 & 274.330 & 0 & 0,00 & 274.330 & 100,00 \\
1846 & 21.298 & 0 & 0,00 & 21.298 & 100,00 \\
1847 & 225.481 & 0 & 0,00 & 225.481 & 100,00 \\
1848 & 314.352 & 16.205 & 5,16 & 298.147 & 94,84 \\
1849 & 559.969 & 35.443 & 6,33 & 524.526 & 93,67 \\
1850 & 390.731 & 59.648 & 15,27 & 331.083 & 84,73
\end{tabular}

* Datos sólo del segundo semestre.

Fuente: A las citadas en el cuadro 1 hay que agregarles: entradas terrestres (1836-1839): registro oficial... Cit. y AGN, división nacional, sección contaduría, receptoría, cargo y data, 1840-1850, núms. 23-139, cargo, contribución, III-24-5-5 a III-26-1-2 (sobre un total de 23.066 operaciones). 
Algo similar sucede con Cuyo, que, salvo en los períodos de bloqueo, no tiene lazos demasiado estrechos con Buenos Aires; en todo caso, mantiene bajos niveles de participación en la totalidad del monto. Chile se convierte así en la mejor —y a veces única — alternativa para la salida de los excedentes de su producción y la importación de lo imprescindible, aunque tampoco en este caso poseemos datos puntuales. ${ }^{14}$

El problema del aporte de la región bonaerense ha sido contemplado, como anticipamos, a través del análisis de las exportaciones del puerto de Buenos Aires. A las cifras del comercio exterior se le han deducido las de los flujos mercantiles desde el Interior y ello permitió completar, al menos a grandes rasgos, el mapa de la producción regional del espacio rioplatense.

Los datos sobre cueros vacunos apuntalan la pujanza de la provincia de Buenos Aires, basada principalmente en la producción de su campaña sureña. Salvo los datos de algunos años para los cueros caballares y la lana que señalan que son las provincias, especialmente las litoraleñas (junto a la sub-región Uruguay), las que más aportan al flujo exportador, los registros de exportación confirman el rotundo predominio de la producción pecuaria de la campaña bonaerense.

\section{GRÁFICO I}

EXPORTACIONES DE BUENOS AIRES

CUEROS VACUNOS, 1835-1854

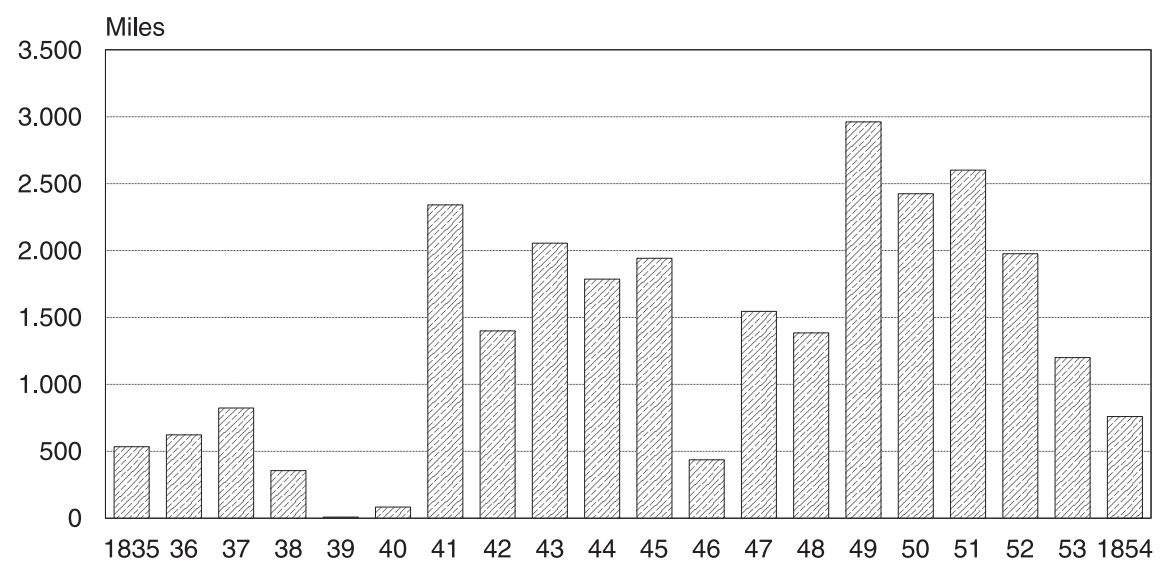

Incluye cueros secos y salados. 1854, datos del primer semestre.

14 Segreti, Carlos: La economía del Interior en la primera mitad del siglo XIX. (Correlación de documentos). I: Cuyo. Buenos Aires, 1981. 


\section{GRÁFICO II}

EXPORTACIÓN DE CUEROS VACUNOS

BUENOS AIRES FRENTE AL INTERIOR, 1836-1850

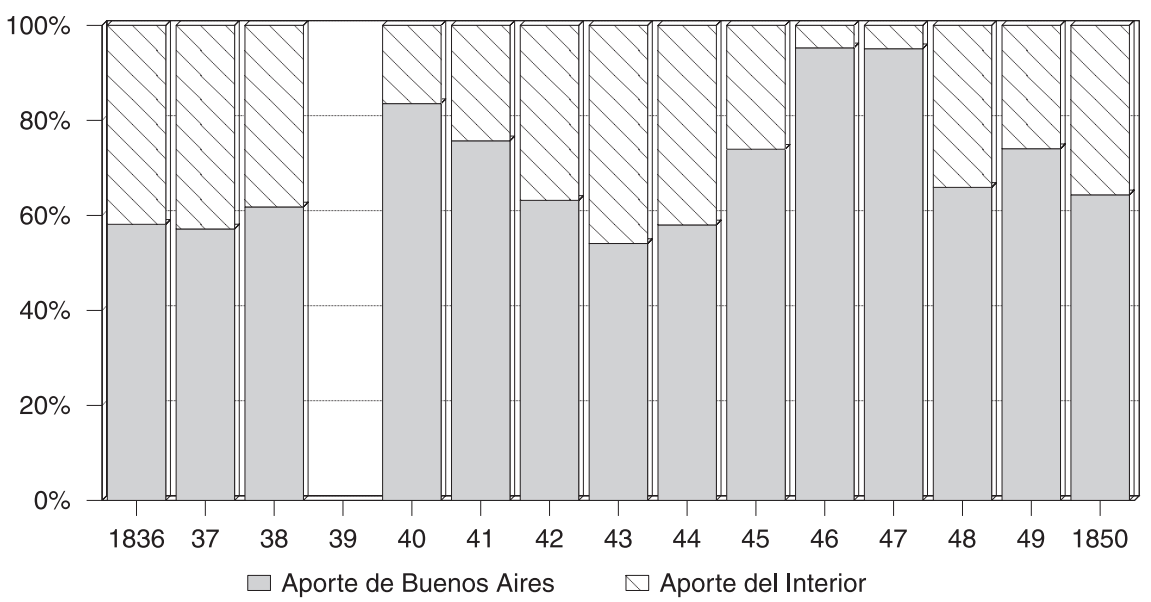

1836, datos del segundo semestre.

\section{GRÁFICO III \\ EXPORTACIÓN DE CUEROS VACUNOS \\ APORTES REGIONALES, 1840-1850}

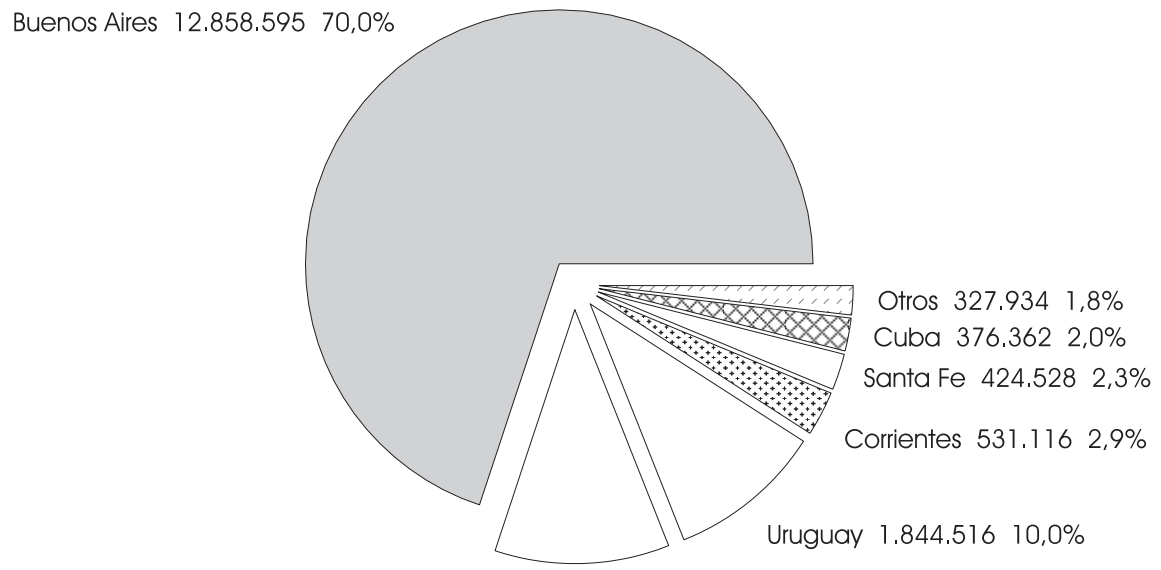

Entre Ríos $1.996 .629 \quad 10,9 \%$

Sobre 18.359.685 cueros vacunos. 


\section{El problema del valor de las exportaciones}

Para el caso del valor de los cueros vacunos, no nos es posible utilizar la serie de precios pecuarios elaborada por Julio Broide ${ }^{15}$ pues se refiere a "la pesada de 35 libras y la mejor calidad de cueros de buey" y no a unidades, tal como aparecen en nuestras fuentes y en donde se engloban distintas calidades ${ }^{16}$ (de macho, de vaca, de desecho) e incluso no siempre están bien diferenciados los cueros secos de los salados, lo cual nos obligó a tratarlos como un todo. Además, la fuente utilizada ni siquiera los afora -lo cual nos daría cierta idea sobre los precios-,${ }^{17}$ sólo indica el cobro de un peso de "salida" por cada unidad, lo mismo que sucede con los cueros baguales, ya sean secos o salados.

También el tasajo puede ser de mala calidad. Hay casos en que se exporta "carne vieja de desecho" a muy bajos precios. Debemos aclarar que el tasajo es el único producto, de los cuatro aquí estudiados, que recibe una valoración de aforo y sobre la cual se paga un 4 \% de "salida".

$\mathrm{Al}$ respecto, hemos manejado los valores del tasajo consignados en el Registro Oficial entre 1835 y 1840, y los "precios" de aforo extraídos de la "Salida" entre el último de los años citados y 1848, lo cual nos da un panorama muy general sin pretender finalizar con la cuestión, en especial porque los valores están expresados en pesos papel.

En síntesis, si bien es cierto que los cueros de desecho y la carne salada de mala calidad no configuran casos demasiado numerosos y no involucran, en general, a grandes cantidades de los productos en cuestión, es evidente que ejercen una influencia probablemente no decisiva, pero de todos modos no despreciable a la hora de tratar de obtener el valor total de las exportaciones.

La lana se constituye en un producto para el cual nuestros datos sobre exportaciones - nos referimos, en especial, a los hallados en nuestro trabajo de archivo de julio de 1840 a junio de 1848 - no son precisos y nos hemos visto obligados a hacer algunas estimaciones; esta falta de precisión

15 Broide, Julio: La evolución de los precios pecuarios argentinos en el período 1830-1850, Buenos Aires, 1951.

16 Algo similar le sucedió a Chiaramonte en su estudio sobre Corrientes: Mercaderes del Litoral..., nota 22 , pág. 245.

17 De todos modos, dentro de la fuente "Cargo y Data", además de la principal sección utilizada en este trabajo, es decir la "Salida", podemos consultar la "Contribución", en cierta medida similar a la primera por sus características fiscales y la cual sí indica el aforo de los productos involucrados en el comercio desde el interior del espacio rioplatense hacia Buenos Aires, tema que nos ha estado ocupando últimamente. 
en la fuente ${ }^{18}$ se debería al hecho de que la lana no pagaba impuesto de "salida". En ocasiones la fuente indica la cantidad de fardos que se embarcan, pero no el número de arrobas que contiene cada uno; en estos casos, se estimó dicho número en 35. Debemos aclarar, sin embargo, que hemos encontrado ejemplos de fardos que contenían más y también menos de lo estimado. En otras se indica que se embarcarán fardos conteniendo diversas cantidades de arrobas, pero finalmente se embarcan menos y no se aclara qué número de las mismas contienen los fardos embarcados. También sucede que en los embarques se mezclan fardos de lana y de cueros de carnero, los cuales tampoco pagaban derecho de "salida". Para terminar, en contados casos se aclara si es lana sucia o lavada.

\section{CUADRO 3: VALOR DEL TASAJO EXPORTADO POR EL PUERTO DE BUENOS AIRES, 1835-1848}

\begin{tabular}{|c|c|c|c|}
\hline Años & Total en qq. & Precio total $*$ & Precio promedio \\
\hline 1. ${ }^{\text {er }}$ sem. 1835 & 66.161 & 874.861 & 13,22 \\
\hline 2. ${ }^{\circ}$ sem. 1835 & 52.856 & 660.702 & 12,50 \\
\hline 1. ${ }^{\text {er }}$ sem. 1836 & 42.600 & 559.461 & 13,13 \\
\hline 2. ${ }^{\circ}$ sem. 1836 & 107.979 & 1.832 .450 & 16,97 \\
\hline 1. ${ }^{\text {er }}$ sem. 1837 & 73.670 & 838.432 & 11,38 \\
\hline 2. ${ }^{\circ}$ sem. 1837 & 105.207 & 1.464 .478 & 13,92 \\
\hline 1. ${ }^{\text {er }}$ sem. 1838 & 147.054 & 1.997 .379 & 13,58 \\
\hline 2. ${ }^{\circ}$ sem. 1838 & 18.250 & 292.008 & 16,00 \\
\hline 1. ${ }^{\text {er }}$ sem. 1839 & 6.670 & 106.720 & 16,00 \\
\hline 2. ${ }^{\circ}$ sem. 1839 & - & - & - \\
\hline 1. ${ }^{\mathrm{er}}$ sem. 1840 & - & - & - \\
\hline 2. ${ }^{\circ}$ sem. 1840 & 8.630 & 129.650 & 15,02 \\
\hline 1841 & 217.671 & 4.793 .830 & 22,02 \\
\hline 1842 & 133.795 & 2.303 .801 & 17,22 \\
\hline 1843 & 182.940 & 5.162 .134 & 28,22 \\
\hline 1844 & 328.182 & 7.236 .815 & 22,05 \\
\hline 1845 & 274.330 & 5.618 .836 & 20,48 \\
\hline 1846 & 21.298 & 629.075 & 29,54 \\
\hline 1847 & 225.481 & 7.023 .405 & 31,15 \\
\hline 1. ${ }^{\text {er }}$ sem. 1848 & 104.917 & 3.565 .275 & 33,98 \\
\hline $\begin{array}{r}* \text { Valores } \\
\text { Fuente: } 18 \\
\text { 1848: AGN, salid }\end{array}$ & $\begin{array}{l}\text { n pesos papel. } \\
\text { stre de 1840: re }\end{array}$ & ial cit.; 2. ${ }^{\circ}$ semest & $1840-1{ }^{\text {er }}$ semestre de \\
\hline
\end{tabular}


En cuanto a las cifras de Parish, el cual indica la cantidad de fardos y bolsones de lana embarcados, hemos estimado en 35 arrobas la cantidad contenida en los mismos. En síntesis, desde el punto de vista cuantitativo, los embarques de lana son sólo estimativos, y las cifras de exportación de la misma son las más endebles de todo el trabajo, lo cual dificulta aún más el tratar de establecer el valor de dicho flujo.

Los porcentajes surgidos de los datos consignados en Registro Oficial de la Provincia de Buenos Aires para los años 1835-1838 indican que el promedio del valor de los cueros vacunos y baguales, la lana y el tasajo ascendió a un $62,48 \%$, si bien el bloqueo que sufrió el puerto de Buenos Aires a partir de 1838 sin duda influyó negativamente en la evolución de dicho año

\section{CUADRO 4: VALOR DE LOS CUEROS VACUNOS Y BAGUALES, LA LANA Y EL TASAJO EN EL TOTAL DE LAS EXPORTACIONES DEL PUERTO DE BUENOS AIRES, 1835-1. ${ }^{\text {er }}$ SEMESTRE DE 1840}

\begin{tabular}{lrrr} 
Años & Valor exportaciones* & Valor productos pecuarios & $\%$ \\
\hline 1835 & 25.357 .492 & 16.666 .840 & 65,73 \\
1836 & 31.876 .335 & 17.986 .026 & 56,42 \\
1837 & 36.641 .398 & 24.069 .033 & 65,69 \\
1838 & 20.764 .483 & 12.890 .361 & 62,08 \\
1839 & 4.223 .674 & 732.930 & 17,35 \\
1840 & 2.094 .176 & 59.640 & 2,85 \\
& & \\
\multicolumn{2}{c}{ * Valores en pesos papel. } & & \\
\multicolumn{2}{l}{ Fuente: Registro oficial... Cit. }
\end{tabular}

Con respecto a este tema, Halperín Donghi afirma: "A lo largo de la primera mitad del siglo XIX los cueros nunca constituyeron menos del 60 por ciento del total de las exportaciones, en valor; muy frecuentemente proporcionaban más del $70 \%$ de ese total. El resto estaba constituido en buena parte por exportaciones complementarias de las de cuero: otros productos de la industrialización del vacuno, básicamente carne salada y sebo (pero también, por valores mucho menores, astas, huesos para botones y para abono, crin...) completan, hasta mediados de la década del 40, alrededor del $90 \%$ del valor total de las exportaciones". ${ }^{19}$

19 Halperín Donghi: “La expansión ganadera ...”, pág. 59. 
Las estimaciones de Halperín Donghi se acercarían más a las cifras brindadas por Parish para el período julio de 1848 a finales de 1851, cuando el promedio del valor de los cuatro productos en el total exportado alcanzó el 77,58 \%.

\section{CUADRO 5: VALOR DE LOS CUEROS VACUNOS Y BAGUALES, LA LANA \\ Y EL TASAJO EN EL TOTAL DE LAS EXPORTACIONES DEL PUERTO \\ DE BUENOS AIRES, $2 .^{\circ}$ SEMESTRE DE 1848-1851}

\begin{tabular}{cccc} 
Años & Valor exportaciones* & Valor productos pecuarios & $\%$ \\
\hline 1848 & 1.091 .604 & 782.332 & 71,67 \\
1849 & 2.537 .821 & 2.016 .459 & 79,46 \\
1850 & 1.983 .513 & 1.554 .499 & 78,37 \\
1851 & 2.126 .705 & 1.718 .896 & 80,82
\end{tabular}

* Valores en libras esterlinas.

Fuente: Parish, Buenos Aires y las provincias... Cit., pág. 512.

Sin embargo, los datos de Parish — al menos para los cuatro productos aquí analizados - deben tomarse con cierta reserva. En principio, dentro de los cueros vacunos incluye secos y salados, de vaca y de novillo, y probablemente algunos de desecho; algo similar sucede con los cueros baguales. En cuanto a la lana, indica la cantidad de fardos y "bolsones" - término que no ha aparecido en las fuentes que revisamos-, pero no el número de arrobas que los mismos contienen; ${ }^{20}$ tampoco desagrega la lana sucia de la lavada. Por último, el tasajo consignado es muy probable que incluyera "carne de baja calidad". Aun así, Parish utiliza un "regulador" - en moneda británica - para cada uno de los productos exportados y que, además, permanece inalterable a lo largo del lapso indicado. ${ }^{21}$

20 Parish indica, para 1851, que "la lana que se exporta hoy se calcula en no menos de" 16 millones de libras, y cada arroba "es de 25 libras", lo cual daría como resultado 640.000 arrobas. Como para dicho año consigna la exportación de 21.974 fardos y bolsones de lana, cada uno debía contener 29,13 arrobas. Sin embargo, la propia estimación de Parish sugeriría una exportación aún mayor. Parish: Buenos Aires y las provincias..., págs. 518 y 522.

21 Parish, al tratar las exportaciones de los años 1852 y 1853 aclara que no "ha sido posible encontrar regulador por el cual se pudiese computar acertadamente el valor de estas exportaciones". Para el período julio de 1848-diciembre de 1851 utiliza, los siguientes valores: 10 chelines para los cueros vacunos, 3 chelines y 9 peniques para los baguales, 10 libras para el fardo o bolsón de lana y 8 chelines para el quintal de tasajo. Parish: Buenos Aires y las provincias ..., págs. 512-513. Burgin también critica la utilización de precios medios. Burgin: Aspectos económicos ..., págs. 338-339. 
MIGUEL ÁNGEL ROSAL

\section{Destino de las exportaciones}

Asimismo hemos considerado algunas cuestiones referentes al destino de las exportaciones entre julio de 1840 y junio de 1848, a través de nuestro trabajo de archivo, y aquéllas producidas entre 1850 y 1853, tal como las consigna Parish

CUADRO 6: DESTINO DE LAS EXPORTACIONES DE CUEROS VACUNO DEL PUERTO DE BUENOS AIRES, JULIO DE 1840-JUNIO DE 1848/1850-1853.

\begin{tabular}{|c|c|c|c|c|c|c|c|}
\hline Destino & 1840 & 1841 & 1842 & 1843 & 1844 & 1845 & 1846 \\
\hline Alemania & 9.081 & 138.839 & 75.023 & 89.037 & 90.655 & 195.814 & 0 \\
\hline Bélgica & 18.328 & 101.309 & 30.403 & 103.622 & 107.503 & 294.122 & 0 \\
\hline Brasil & 5.400 & 20.927 & 36.435 & 27.964 & 5.362 & 37.448 & 393.156 \\
\hline Cuba & 0 & 25 & 237 & 164 & 1.147 & 1.282 & 455 \\
\hline España & 26.840 & 219.369 & 188.371 & 278.258 & 169.769 & 202.300 & 0 \\
\hline Francia & 0 & 288.330 & 292.721 & 396.146 & 225.059 & 258.368 & 0 \\
\hline Gran Bretaña & 11.298 & 947.133 & 385.531 & 648.049 & 862.125 & 660.583 & 0 \\
\hline Holanda & 0 & 68.385 & 11.096 & 23.193 & 11.268 & 0 & 0 \\
\hline Italia & 7.388 & 91.801 & 98.777 & 143.538 & 64.656 & 93.298 & 3.000 \\
\hline Portugal & 0 & 100 & 2.000 & 500 & 7.217 & 0 & 0 \\
\hline Uruguay & 2.417 & 0 & 24 & 271 & 0 & 0 & 10.252 \\
\hline USA & 874 & 415.917 & 278.853 & 343.893 & 241.574 & 199.082 & 21.576 \\
\hline Otros & 0 & 48.503 & 0 & 80 & 16 & 0 & 8.300 \\
\hline Total & 81.626 & 2.340 .638 & 1.399 .471 & 2.054 .715 & 1.786 .351 & 1.942 .297 & 436.739 \\
\hline Destino & 1847 & 1848 & 1850 & 1851 & 1852 & 1853 & Tot. gral. \\
\hline Alemania & 9.024 & 0 & 602.550 & 615.184 & 470.986 & 282.518 & 2.578 .711 \\
\hline Bélgica & 30.866 & 32.623 & 0 & 0 & 0 & 0 & 718.776 \\
\hline Brasil & 1.286 .290 & 118.865 & 7.746 & 1.446 & 2.752 & 2.176 & 1.945 .967 \\
\hline Cuba & 8.613 & 882 & 3.522 & 4.069 & 2.019 & 1.623 & 24.038 \\
\hline España & 26.044 & 24.353 & 164.680 & 214.327 & 175.830 & 101.769 & 1.791 .910 \\
\hline Francia & 1.316 & 1.460 & 322.940 & 279.704 & 214.014 & 107.835 & 2.387 .893 \\
\hline Gran Bretaña & 57.829 & 34.485 & 383.831 & 596.526 & 374.617 & 318.786 & 5.280 .793 \\
\hline Holanda & 0 & 0 & 0 & 0 & 0 & 0 & 113.942 \\
\hline Italia & 8.823 & 13.083 & 197.771 & 193.304 & 250.091 & 105.650 & 1.271 .180 \\
\hline Portugal & 0 & 0 & 0 & 0 & 0 & 0 & 9.817 \\
\hline Uruguay & 70.644 & 0 & 0 & 0 & 0 & 0 & 83.608 \\
\hline USA & 41.796 & 57.946 & 741.113 & 696.580 & 504.073 & 285.394 & 3.828 .671 \\
\hline Otros & 4.062 & 0 & 0 & 0 & 0 & 0 & 60.961 \\
\hline Total & 1.545 .307 & 283.697 & 424.153 & 2.601 .140 & .994 .382 & 1.205 .751 & 20.096 .267 \\
\hline
\end{tabular}

Fuente: $2 .^{\circ}$ semestre de $1840-1$ er $^{\text {er }}$ semestre de 1848: AGN, salida cit.; 1850-1953: Parish, Buenos Aires y las provincias..., págs. 514-517.

580

Anuario de Estudios Americanos 
Gran Bretaña continúa siendo la principal destinataria de los cueros vacunos y baguales, si bien las importaciones de Norteamérica de dichos bienes van incrementándose. En cuanto a la lana, son los Estados Unidos nuestros mejores compradores, y es significativo el rol desempeñado por Francia y Alemania, además del jugado por los ingleses. Obviamente, el tasajo era enviado casi exclusivamente hacia Brasil y la isla de Cuba. (ver cuadros 7 a 10 en el Apéndice)
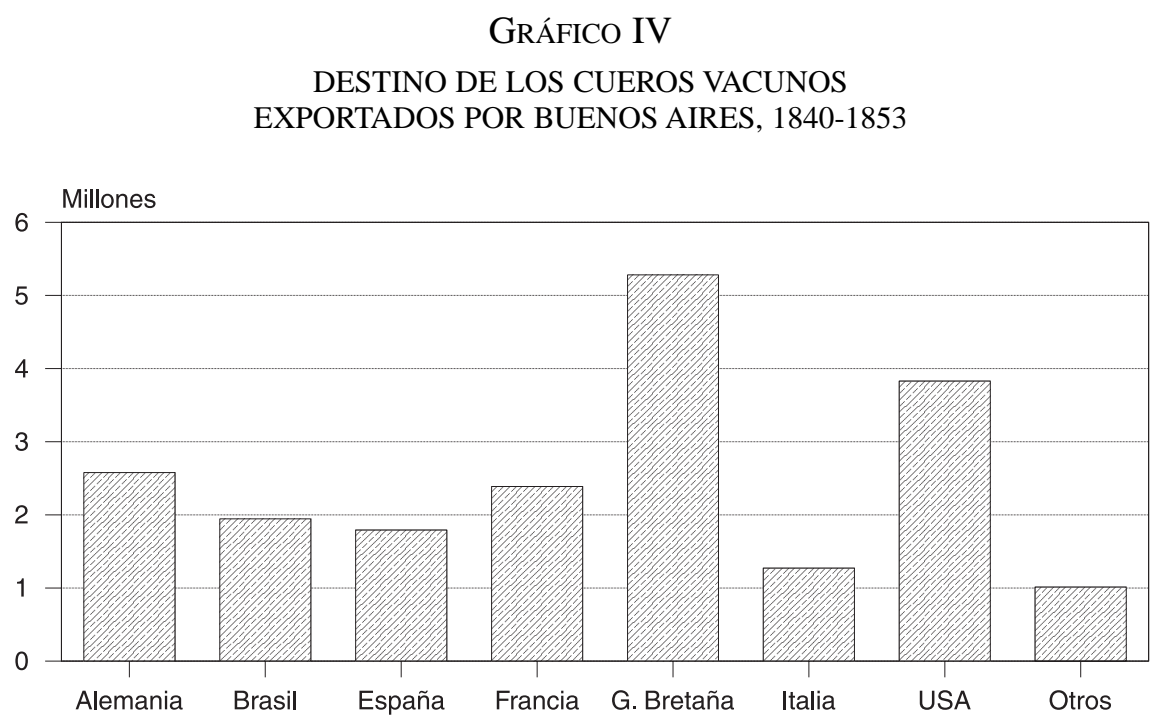

Faltan datos de ene.-jun. de 1840 y de jul. de 1848-dic. de 1849. Sobre 20.096.267 cueros vacunos.

Los productos pecuarios rioplatenses tenían como destino los puertos - tal como aparecen en nuestras fuentes- de Río Grande, Santa Catalina, Paranaguá, Santos, Río de Janeiro, Bahía y Pernambuco, en Brasil; los de La Habana y Matanzas, en la isla de Cuba; los de Nueva York, Boston, Baltimore, Filadelfia y Salem, en Norteamérica: los de Londres, Liverpool, Cowes, Falmouth, Plymouth, Halifax, Exeter, Newcastle y Cork (Irlanda), en Gran Bretaña; los de El Havre, Burdeos, Nantes, Marsella y Cette (Séte), en Francia; los de Lisboa y Oporto, en Portugal; los de Cádiz, Málaga, Barcelona, La Coruña, Ribadeo, Santander y Bilbao, en España, además de los puertos alemanes de Bremen, Hamburgo y Altona, los de 
Amberes, Rotterdam y Amsterdam, en los Países Bajos, y los de Génova y Trieste, en la península itálica, unidos a los de la isla de Sicilia; encontramos también unas pocas remesas hacia las islas Bermudas, hacia la costa de Africa y hacia Valparaíso.

Un párrafo aparte merecen las exportaciones correspondientes al lapso 1846-1848, época en que el puerto de Buenos Aires estuvo bloqueado por la flota anglofrancesa. Los cueros y la lana iban esencialmente a Brasil, en especial a Río Grande, aunque es probable que finalmente estos productos fueran transportados a puertos europeos o norteamericanos. Los navíos utilizados son, generalmente, goletas, balandras, balleneras y pailebotes (es decir, embarcaciones de porte menor) de bandera nacional..$^{22}$ Pensamos que los productos que se dirigían a Uruguay - prácticamente la totalidad lo hace hacia Montevideo - tenían como destino final otros mercados, muy probablemente Europa o Estados Unidos, con escala en puertos brasileños, sin embargo la fuente no hace precisiones al respecto. El tasajo destinado a La Habana se embarcaba en pequeños navíos de bandera nacional y era trasladado hacia la rada de Montevideo, donde se trasbordaba a naves de mayor porte, generalmente bergantines, de bandera española.

\section{Observaciones finales}

El proceso por el cual las relaciones económicas internacionales establecidas desde fines del siglo XVIII, en donde algunas naciones, la mayoría, aportaba materias primas que motorizaban la industrialización europea, muy especialmente la inglesa, y otras, unas pocas, introducían en el mercado mundial productos manufacturados, se acentuó a lo largo de la siguiente centuria. En el contexto de la división internacional del trabajo estrictamente implementada, el Río de la Plata participará decididamente a partir de 1810 como proveedora de productos primarios provenientes de su ganadería. Este patrón comercial exterior — privado ya de los flujos de la plata potosina, principal bien exportable durante la época colonial, dada la incapacidad de los porteños para controlar militarmente la región altoperuana - regirá sin cambios apreciables durante varios lustros, algunos de los cuales han sido objeto de este estudio.

22 Es decir que el bloqueo funcionó de manera bastante estricta al impedir la entrada de mercancías europeas a Buenos Aires, pero fue más laxo en cuanto a la salida de frutos, pues permitió a los porteños exportar parte de su producción pecuaria. 
La exportación de cueros, en especial de los vacunos, y de tasajo va incrementándose a lo largo de la primera mitad del siglo XIX, mientras que hacia el final del período, aún con incierta evolución, comienza a vislumbrarse el significativo rol que la lana tendrá en las exportaciones porteñas de la segunda parte de la centuria.

Este análisis del comercio exterior nos ha permitido, además, aportar elementos de juicio que ayuden a bosquejar, si bien en términos generales, el mapa productivo del espacio rioplatense. A las cifras de exportaciones les hemos deducido las de los flujos mercantiles del Interior, lo cual estaría indicando, en forma global, cuál es el aporte de la principal región en que hemos dividido el territorio, es decir, la campaña de Buenos Aires.

Si bien hemos podido establecer con bastante seguridad las cifras de exportación de los productos pecuarios más significativos de estas regiones - aun cuando sobre la lana nos hemos visto obligados a hacer, en ocasiones, algunas estimaciones-, las características de las fuentes consultadas nos han impedido realizar, salvo en una forma muy generalizada, la tarea de obtener la evaluación de dicho comercio exterior.

Por último, teniendo en cuenta el destino de nuestras exportaciones, Gran Bretaña y Estados Unidos de Norteamérica son los principales compradores de los cueros y la lana, respectivamente, y son apreciables las remesas enviadas hacia puertos franceses y alemanes; el tasajo, por su parte, tendrá como destino preferencial los de Brasil y el de La Habana. 


\section{Apéndice estadístico}

\section{CUADRO 7: DESTINO DE LAS EXPORTACIONES DEL PUERTO \\ DE BUENOS AIRES, SEGUNDO SEMESTRE DE 1840-1842}

$2 .^{\circ}$ semestre de 1840

\begin{tabular}{lrrrr} 
Destino & Cueros vacunos & Cueros baguales & Lana & Tasajo \\
\hline Alemania & 9.081 & 0 & 0 & 0 \\
Bélgica & 18.328 & 0 & 0 & 0 \\
Brasil & 5.400 & 0 & 0 & 8.630 \\
España & 26.840 & 0 & 0 & 0 \\
Gran Bretaña & 11.298 & 3.817 & 1.993 & 0 \\
Italia & 7.388 & 0 & 0 & 0 \\
Uruguay & 2.417 & 0 & 0 & 0 \\
USA & 874 & 680 & 1.575 & 0 \\
Total & 81.626 & 4.497 & 3.568 & 8.630
\end{tabular}

1841

\begin{tabular}{lccrr} 
Destino & Cueros vacunos & Cueros baguales & Lana & Tasajo \\
\hline Alemania & 138.839 & 0 & 437 & 0 \\
Bélgica & 101.309 & 500 & 8.546 & 0 \\
Brasil & 20.927 & 300 & 14 & 93.859 \\
Cuba & 25 & 0 & 0 & 122.400 \\
España & 219.369 & 9.974 & 1.563 & 0 \\
Francia & 288.330 & 640 & 36.411 & 0 \\
Gran Bretaña & 947.133 & 77.848 & 52.601 & 0 \\
Holanda & 68.385 & 0 & 0 & 0 \\
Italia & 91.801 & 667 & 18.313 & 0 \\
Portugal & 100 & 0 & 0 & 0 \\
USA & 415.917 & 22.448 & 186.987 & 1.412 \\
Otros (Europa) & 48.503 & 815 & 0 & 0 \\
Total & 2.340 .638 & 113.192 & 304.872 & 217.671
\end{tabular}

1842

\begin{tabular}{lcrrr} 
Destino & Cueros vacunos & Cueros baguales & Lana & Tasajo \\
\hline Alemania & 75.023 & 249 & 750 & 0 \\
Bélgica & 30.403 & 0 & 1.159 & 0 \\
Brasil & 36.435 & 36 & 0 & 65.291 \\
Cuba & 237 & 0 & 0 & 62.924 \\
España & 188.371 & 7.547 & 1.207 & 0 \\
Francia & 292.721 & 6.347 & 55.523 & 0 \\
Gran Bretaña & 385.531 & 35.491 & 10.126 & 70 \\
Holanda & 11.096 & 0 & 24 & 0 \\
Italia & 98.777 & 2.173 & 15.284 & 0 \\
Portugal & 2.000 & 0 & 0 & 0 \\
Uruguay & 24 & 0 & 30 & 0 \\
USA & 278.853 & 6.665 & 40.593 & 5.510 \\
\hline Total & 1.399 .471 & 58.508 & 124.696 & 133.795
\end{tabular}

Fuente: AGN, salida cit., (sobre un total de 2.457 notas de embarque). 
MIGUEL ÁNGEL ROSAL

CUADRO 8: DESTINO DE LAS EXPORTACIONES

DEL PUERTO DE BUENOS AIRES, 1843-1845

1843

\begin{tabular}{lrrrr} 
Destino & Cueros vacunos & Cueros baguales & Lana & Tasajo \\
\hline Alemania & 89.037 & 220 & 0 & 0 \\
Bélgica & 103.622 & 1.963 & 5.847 & 0 \\
Brasil & 27.964 & 0 & 36 & 81.069 \\
Cuba & 164 & 0 & 0 & 99.652 \\
Chile & 80 & 0 & 0 & 0 \\
España & 278.258 & 5.953 & 1.481 & 0 \\
Francia & 396.146 & 24.489 & 70.850 & 0 \\
Gran Bretaña & 648.049 & 34.986 & 20.566 & 0 \\
Holanda & 23.193 & 0 & 0 & 0 \\
Italia & 143.538 & 3.647 & 24.790 & 0 \\
Portugal & 500 & 0 & 0 & 0 \\
Uruguay & 271 & 0 & 0 & 0 \\
USA & 343.893 & 546 & 49.065 & 2.219 \\
\hline Total & 2.054 .715 & 71.804 & 172.635 & 182.940
\end{tabular}

1844

\begin{tabular}{lrrrr} 
Destino & Cueros vacunos & Cueros baguales & Lana & Tasajo \\
\hline Alemania & 90.655 & 80 & 0 & 0 \\
Bélgica & 107.503 & 0 & 0 & 0 \\
Brasil & 5.362 & 1 & 40 & 123.214 \\
Cuba & 1.147 & 0 & 105 & 204.901 \\
España & 169.769 & 1.070 & 65 & 0 \\
Francia & 225.059 & 480 & 37.625 & 3 \\
Gran Bretaña & 862.125 & 38.448 & 12.900 & 4 \\
Holanda & 11.268 & 0 & 0 & 10 \\
Italia & 64.656 & 383 & 22.367 & 0 \\
Portugal & 7.217 & 0 & 0 & 0 \\
USA & 241.574 & 1.184 & 66.113 & 0 \\
Otros & 16 & 0 & 0 & 50 \\
Total & 1.786 .351 & 41.646 & 139.215 & 328.182 \\
& & 1845 & &
\end{tabular}

\begin{tabular}{lccrr} 
Destino & Cueros vacunos & Cueros baguales & Lana & Tasajo \\
\hline Alemania & 195.814 & 0 & 669 & 0 \\
Bélgica & 294.122 & 0 & 8.190 & 0 \\
Brasil & 37.448 & 2.790 & 1.407 & 98.205 \\
Cuba & 1.282 & 0 & 21 & 176.125 \\
España & 202.300 & 2.206 & 287 & 0 \\
Francia & 258.368 & 200 & 38.677 & 0 \\
Gran Bretaña & 660.583 & 63.026 & 18.126 & 0 \\
Italia & 93.298 & 460 & 17.870 & 0 \\
USA & 199.082 & 730 & 87.262 & 0 \\
\hline Total & 1.942 .297 & 69.412 & 172.509 & 274.330
\end{tabular}

Fuente: AGN, salida cit., (sobre un total de 3.940 notas de embarque). 
EXPORTACIONES DEL PUERTO DE BUENOS AIRES ENTRE 1835 Y 1854

CUADRO 9: DESTINO DE LAS EXPORTACIONES DEL PUERTO

DE BUENOS AIRES, 1846-PRIMER SEMESTRE DE 1848

1846

\begin{tabular}{lrrrr} 
Destino & Cueros vacunos & Cueros baguales & \multicolumn{1}{c}{ Lana } & Tasajo \\
\hline Brasil & 393.156 & 53.662 & 60.943 & 0 \\
Cuba & 455 & 0 & 0 & 21.298 \\
Italia & 3.000 & 0 & 0 & 0 \\
Uruguay & 10.252 & 995 & 4.084 & 0 \\
USA & 21.576 & 206 & 170 & 0 \\
Otros & 8.300 & 0 & 0 & 0 \\
Total & 436.739 & 54.863 & 65.197 & 21.298
\end{tabular}

1847

\begin{tabular}{lrrrr} 
Destino & Cueros vacunos & Cueros baguales & Lana & Tasajo \\
\hline Alemania & 9.024 & 0 & 0 & 0 \\
Bélgica & 30.866 & 0 & 0 & 0 \\
Brasil & 1.286 .290 & 94.139 & 301.857 & 33.469 \\
Cuba & 8.613 & 0 & 0 & 188.789 \\
España & 26.044 & 0 & 0 & 0 \\
Francia & 1.316 & 710 & 0 & 18 \\
Gran Bretaña & 57.829 & 10.790 & 2.635 & 789 \\
Italia & 8.823 & 0 & 0 & 0 \\
Uruguay & 70.644 & 2.466 & 8.641 & 0 \\
USA & 41.796 & 78 & 3.969 & 2.416 \\
Otros & 4.062 & 0 & 0 & 0 \\
\hline Total & 1.545 .307 & 108.183 & 317.102 & 225.481
\end{tabular}

$1{ }^{\text {er }}$ semestre de 1848

\begin{tabular}{lrrrr} 
Destino & Cueros vacunos & Cueros baguales & Lana & Tasajo \\
\hline Bélgica & 32.623 & 530 & 0 & 0 \\
Brasil & 118.865 & 853 & 0 & 23.797 \\
Cuba & 882 & 0 & 0 & 81.120 \\
España & 24.353 & 0 & 0 & 0 \\
Francia & 1.460 & 0 & 0 & 0 \\
Gran Bretaña & 34.485 & 27.625 & 0 & 0 \\
Italia & 13.083 & 0 & 6.300 & 0 \\
USA & 57.946 & 2.619 & 23.740 & 0 \\
\hline Total & 283.697 & 31.627 & 30.040 & 104.917
\end{tabular}

Fuente: AGN, salida cit., (sobre un total de 3.622 notas de embarque). 
MIGUEL ÁNGEL ROSAL

CUADRO 10: DESTINO DE LAS EXPORTACIONES
DEL PUERTO DE BUENOS AIRES, 1850-1853

\begin{tabular}{|c|c|c|c|c|}
\hline 1850 & Cueros vacunos & Cueros baguales & Lana & Tasajo \\
\hline Gran Bretaña & 383.831 & 103.520 & 57.645 & - \\
\hline Francia & 322.940 & 10.445 & 73.430 & - \\
\hline Alemania & 602.550 & 1.165 & 60.830 & - \\
\hline Italia & 197.771 & 35.018 & 17.535 & - \\
\hline España & 164.680 & 12.904 & 35 & - \\
\hline La Habana & 3.522 & - & - & 254.011 \\
\hline Est. Unidos & 741.113 & 21.050 & 532.525 & - \\
\hline Brasil & 7.746 & - & - & 136.720 \\
\hline Total gral. & 2.424 .153 & 184.102 & 742.000 & 390.731 \\
\hline 1851 & Cueros vacunos & Cueros baguales & Lana & Tasajo \\
\hline Gran Bretaña & 596.526 & 61.767 & 44.415 & - \\
\hline Francia & 279.704 & 19.741 & 30.485 & - \\
\hline Alemania & 615.184 & 2.158 & 27.055 & - \\
\hline Italia & 193.304 & 2.710 & 26.880 & - \\
\hline España & 214.327 & 19.841 & - & - \\
\hline La Habana & 4.069 & - & - & 270.915 \\
\hline Est. Unidos & 696.580 & 34.400 & 640.255 & - \\
\hline Brasil & 1.446 & 60 & - & 160.959 \\
\hline Total gral. & 2.601 .140 & 140.677 & 769.090 & 431.874 \\
\hline 1852 & Cueros vacunos & Cueros baguales & Lana & Tasajo \\
\hline Gran Bretaña & 374.617 & 54.225 & 151.830 & - \\
\hline Francia & 214.014 & 6.600 & 127.365 & - \\
\hline Alemania & 470.986 & 3.621 & 115.500 & - \\
\hline Italia & 250.091 & 13.787 & 26.495 & - \\
\hline España & 175.830 & 2.255 & 140 & - \\
\hline La Habana & 2.019 & - & - & 296.095 \\
\hline Est. Unidos & 504.073 & 25.362 & 298.340 & - \\
\hline Brasil & 2.752 & - & - & 234.865 \\
\hline Total gral. & 1.994 .382 & 105.850 & 719.670 & 530.960 \\
\hline 1853 & Cueros vacunos & Cueros baguales & Lana & Tasajo \\
\hline Gran Bretaña & 318.786 & 113.593 & 246.085 & - \\
\hline Francia & 107.835 & 3.958 & 164.360 & - \\
\hline Alemania & 282.518 & 2.244 & 111.160 & - \\
\hline Italia & 105.650 & 791 & 20.860 & - \\
\hline España & 101.769 & 4.304 & - & - \\
\hline La Habana & 1.623 & - & - & 206.184 \\
\hline Est. Unidos & 285.394 & 8.461 & 284.900 & - \\
\hline Brasil & 2.176 & - & - & 129.431 \\
\hline Total gral. & 1.205 .751 & 133.351 & 827.365 & 335.615 \\
\hline
\end{tabular}

Fuente: Parish: Buenos Aires y las provincias... Se aprecian algunas diferencias entre estas cantidades y las totales (págs. 512-513); también muestran cierta disimilitud con las consignadas en la pág. 520.

588

Anuario de Estudios Americanos 